\title{
Roles of nurses and parents caring for hospitalised children
}

\author{
Ella Bedells and Ann Bevan examine the \\ importance of nurse-parent relationships and \\ communication in the care of children in hospital
}

\begin{abstract}
Correspondence
ellabedells@hotmail.co.uk

Ella Bedells is an

undergraduate student

Ann Bevan is a senior lecturer and programme lead
\end{abstract}

Both at Bournemouth University, Dorset

Date of submission

July 222015

Date of acceptance

October 92015

Peer review

This article has been subject

to double-blind review and

has been checked using

antiplagiarism software

Author guidelines

journals.rcni.com/r/

ncyp-author-guidelines

\begin{abstract}
This article reviews the literature on nurses' and parents' self-perceived roles when caring for hospitalised children, focusing on research conducted since the Department of Health published the National Service Framework for Children: Standard for Hospital Services in 2003. Three main themes emerge from the review: nurses' perceptions, parents' perceptions, and negotiation. Clarification of what nurses and parents consider to be their respective roles when caring for hospitalised children is a prerequisite for negotiation of those roles. The family's background, life experiences and circumstances influencs the effectiveness of negotiation between nurses and parents. The article explores potential barriers to negotiation, including poor communication and failure to provide information. Limitations of the research and the implications for practice are considered.
\end{abstract}

\section{Keywords}

child health, communication, family-centred care, negotiation, nurse-parent relationship, parental care

THE 1959 Ministry of Health Report entitled The Welfare of Children in Hospital, more commonly known as the Platt Report, first introduced family-centred care into children's health care. Since then, seminal work by Casey (1988) and Nethercott (1993) has described and highlighted the importance of parental participation and family involvement in the care of hospitalised children. In 2003, the Department of Health (DH) implemented guidance on family-centred care and partnership working with parents. This means that parents can stay with their children in hospital and participate in their care alongside nurses (Davies 2010).
Although there is a growing body of literature on the views of nurses and parents about their respective roles in caring for hospitalised children, there seems to be no clear consensus as to what these roles are or how they should be negotiated (O'Haire and Blackford 2005). A study by Hughes (2007) found that nurses often assumed parents would wish to participate actively in the nursing care of their hospitalised child. However, some parents showed uncertainty about their role and required a high level of support. Negotiation in this context is considered to be the process of discussion and mutual agreement between the parent and nurse about the shared care of a hospitalised child (Young et al 2006).

This article explores the self-perceived roles of children's nurses and parents, and the clarification and negotiation of these roles, with a view both to ascertaining why such negotiation can be problematic, and to improving student and registered nurses' understanding of the perceived roles and the importance of negotiating them. This is followed by a discussion of what negotiation entails, the importance of negotiation between the parents and the children's nurse, the consequences of a lack of negotiation, and the influence of family background, life experiences and specific circumstances on hospital admissions and desired level of participation in care. The limitations of the research and the implications of the review findings for practice will also be considered.

\section{Search strategy}

The authors searched the British Nursing Index, CINAHL, MEDLINE, PsycINFO and PubMed databases to identify the primary research studies required to undertake this review. They included an asterisk 
applied to obtain every derivation of the search terms and a Boolean phrase technique. They identified further research studies using reference lists from articles that had already been retrieved. Inclusion criteria were:

English language.

- International primary research.

- Research relating to the perceptions held by parents and/or children's nurses of their relationship, roles, and negotiation of these roles when caring for hospitalised children.

Research published between 2003 and 2015. Exclusion criteria were:

Research published before 2003.

Reviews of literature and research into specific condition, illnesses or hospital admissions other than those described as general acute, special needs, chronic illnesses or technology dependent.

- Any research involving the views of individuals other than parents and children's nurses.

- Any research into the influences on parent-nurse partnerships.

After careful evaluation, the authors identified a total of 13 primary research articles. Their review focused on research conducted since the DH (2003) published the National Service Framework for Children, which highlights the importance of nurses providing family-centred care and working in partnership with parents.

\section{Emerging themes}

Nurses' perceptions Nurses appear to view administrative and technical duties, staff supervision and equipment monitoring as part of their role, in addition to functioning as 'facilitators' by supervising and assisting parents in their parenting role (Coyne and Cowley 2007, Coyne 2008). Using a qualitative approach, Paliadelis et al (2005) interviewed 14 children's nurses and found that all of the participants feel strongly about maintaining their professional role as nurses, and were reluctant to delegate control to parents.

Although some nurses said that communicating with, and providing support to, parents is important (Ygge 2007), others said that it was the parents' responsibility to keep communication channels open (Roden 2005). Further analysis of the findings obtained by Roden (2005) revealed that the nurses said this because advice they had given to parents in the past had been ignored.

It appears that nurses expect parents to remain by the bedside of their children, participate appropriately in their care and attend to children's basic care needs (Paliadelis et al 2005, Young et al 2006, Coyne and Cowley 2007, Hughes 2007, Coyne
2008). Similarly, in the study by Paliadelis et al (2005) and in the grounded theory study by Coyne (2008) involving interviews, questionnaires and observations, nurses said they expect parents to keep their children calm and manageable so they can care for them.

In an exploratory study involving ten experienced children's nurses, participants said they often consider parents to be 'experts' in their children's care and often looked to them for guidance (Lee 2007). Similarly, nurses tended to assume that the parents of chronically ill children in particular were knowledgeable about, and competent to, provide care for their children (Coyne 2008).

Parents often became confused when nurses have varying expectations of them (Espezel and Canam 2003). Roden (2005) found that nurses expect parents to be involved in treatment regimes, whereas Young et al (2006), in a questionnaire-based study of 106 children's nurses, reported that nurses do not expect parents to perform 'nurses' work.' The study by Roden (2005) was conducted in a small, non-specialist paediatric setting, in contrast to one by Young et al (2006), which was undertaken in a large paediatric tertiary hospital. It could therefore be assumed that nurses working in tertiary hospitals would provide more specialist care, which would not directly involve parents.

Parents' perceptions Most parents said that their main roles are to stay with their children in hospital and to provide basic care, such as feeding, bathing, providing clean clothes and changing nappies. In these respects their expectations appear to be aligned with those of nurses (Paliadelis et al 2005, Roden 2005, Lam et al 2006, Coyne and Cowley 2007, Avis and Reardon 2008, Sousa et al 2013). Indeed, $97 \%$ of the parents who were interviewed in a study by Sousa et al (2013) said that if they were staying overnight with their children, they should participate fully in their care throughout the night, alongside the nurses. However, it is important to note that parents were invited to participate in this study by nurses on duty, which may have influenced their responses if they thought they could not be open about their concerns.

It has been reported that parents regard remaining by their children's bedside as an 'unconditional aspect' of parenting (Lam et al 2006), although some parents are reluctant to provide nursing care because they have insufficient knowledge (Roden 2005). Avis and Reardon (2008), who interviewed parents of children with special needs, highlight parents' concerns about being expected to provide their children with 
medicine, food and personal care. In the absence of negotiation, it seems that parents think they are powerless and so comply with nurses' requests (Espezel and Canam 2003, Roden 2005, Reeves et al 2006, Coyne and Cowley 2007, Avis and Reardon 2008, Sousa et al 2013). Coyne and Cowley (2007) suggest that parents are not confident that nurses will be available when they need them due to competing demands on their time. Similarly, Hughes (2007) and Reeves et al (2006) report that parents feel obliged to remain with their children because nurses always appear to be busy.

According to Espezel and Canam (2003), parents are grateful when nurses take on the role of communicator. Another study found that parents appreciate nurses communicating with them and reporting changes in their children's care (Lam et al 2006). An inclusion criterion in this study was that parents had remained in hospital with their children for more than 48 hours, which suggests that parents who had stayed for shorter times may have expressed different views. It was also found that parents believe that nurses should perform specific duties, such as recording vital signs, administering medicines and monitoring equipment (Roden 2005, Coyne and Cowley 2007). Parents also expect to receive nursing support in return for the help they give in caring for their children (Roden 2005).

Negotiation Nurses appeared to encourage the negotiation of care, even though some of them admitted that this did not include the clarification of roles (Young et al 2006). Although negotiation is a high priority for some nurses (Young et al 2006), parents still reported that barriers between nurses and parents are not addressed (Roden 2005, Coyne and Cowley 2007, Coyne 2008, Avis and Reardon 2008). However, nurses who were interviewed in the study by Young et al (2006) cared for children with acute medical needs, whereas Avis and Reardon (2008) interviewed the parents of children with special needs. Those who cared for the latter group of children may have assumed that the parents were more competent to provide care for them, and that negotiation was unnecessary.

Negotiation had a great deal of significance for these parents because of the large amount of contact they and their children had with the healthcare system (Sousa et al 2013).

It is recognised that nurses must view parents as equal partners in care if negotiation is to be successful (Lee 2007). However, in the study by Paliadelis et al (2005), nurses said that they discourage parents from taking responsibility for any roles except that of basic parenting during their children's hospitalisation. Failure to engage in negotiation could give rise to feelings of anxiety and stress for parents and nurses, due to the uncertainty about roles and conflicting expectations (Coyne and Cowley 2007, Coyne 2008, Avis and Reardon 2008).

Communication between nurse and parent was valued by parents, who reported a positive hospital experience (Roden 2005), although it was not clear what parents believe constitutes positive nurseparent communication. Despite a general recognition that communication is important, comments about lack of communication and information sharing between nurses and parents are common (Espezel and Canam 2003, Paliadelis et al 2005, Coyne and Cowley 2007, Avis and Reardon 2008, Sousa et al 2013). Hughes (2007) found that more than $50 \%$ of parents admitted that they did not know what was expected of them, and there is evidence to suggest that poor communication may be responsible for parents' reluctance to inform nurses when they are unwilling to participate in the care of their hospitalised children (Sousa et al 2013).

\section{Parent-nurse relationships}

It is evident that, due to a lack of negotiation in the early stages of care, the relationship between nurses and parents is often suboptimal (Coyne and Cowley 2007, Coyne 2008, Avis and Reardon 2008). Conflict between nurses and parents can occur if insufficient time is given to the clarification and negotiation of roles (O'Haire and Blackford 2005, Aein et al 2009, Fisher and Broome 2011, Coyne 2015), and there is evidence to suggest that most conflict is caused by poor communication and failure to provide information (Moore and Kordick 2006).

Negotiation has been shown to be essential for the promotion of effective nurse-parent relationships (Reis et al 2010), and the Nursing and Midwifery Council (2010) has stated in the Standards for Competence for Registered Nurses that nurses should use negotiation skills in all decision making, including decisions about whether to continue or withdraw care. Yet much of the literature included in the authors' review (Roden 2005, Reeves et al 2006, Coyne and Cowley 2007, Avis and Reardon 2008, Coyne 2008) and elsewhere (Corlett and Twycross 2006, Harrison 2010) demonstrates a lack of negotiation. Reasons for non-negotiation, and the potential barriers to negotiation, have been a previous focus of research (Paliadelis et al 2005, Fisher and Broome 2011, Coyne 2015), with poor communication being consistently cited as a root cause. The recently published Core Competences for Nursing Children and Young People (Royal College of Nursing 2012) highlights how important 
it is for nurses to communicate effectively and appropriately with children and young people, as well as with their parents, families and carers.

As parents are now much more involved in their children's care and in decision making, effective communication of information by nurses is vital (Hummelinck and Pollock 2006). However, a recurrent finding in the authors' literature review (Paliadelis et al 2005, Lam et al 2006, Coyne 2015) and other research (Corlett and Twycross 2006, Fisher and Broome 2011) is that parents report a lack of information from nurses.

Little is known about the specific types of information that parents think they need while caring for their children in hospital, and this may explain why it does not seem to be provided (Hummelinck and Pollock 2006). It has recently been found that levels of parental anxiety can be reduced simply through effective communication and by providing parents with information regularly (James et al 2013). Therefore, any attempt to identify the most effective ways to share information with parents would involve improving relationships between nurses and parents, and enhancing care delivery (Fisher and Broome 2011).

Nurses and parents believe that it is part of the role of nurses to provide technical nursing care and offer support to parents. Similarly, it is the view of parents and nurses that parents should provide basic care for their hospitalised children, and should remain by their bedsides to give emotional support. However, it is important not to assume that all parents are comfortable with this caring role.

Although the studies in this literature review did not identify parents who were unwilling to participate in the care of their children, other reports suggest that parents may want to remain uninvolved and do not feel obliged to remain by their children's bedsides (Reeves et al 2006, Hughes 2007). Some parents have been labelled as 'difficult' by nurses when they have not met the nurses' expectations (O'Haire and Blackford 2005, Coyne and Cowley 2007, Coyne 2008, Aein et al 2009). In such situations it is unlikely that parental care has been negotiated because nurses tend to avoid unnecessary communication with 'difficult parents' (O'Haire and Blackford 2005, Coyne 2008).

Family background and life experiences can influence parents' preferred level of participation in care (Paliadelis et al 2005, Lam et al 2006). Similarly, families' specific circumstances may affect the amount of time they can spend in hospital and, consequently, the level of care that they can provide their children (Hopia et al 2005). Parents may view the admission of children with special or chronic health needs to hospital as an opportunity for respite from their role as the main carer (Reeves et al 2006), whereas the parents of children who are acutely unwell and have been admitted to hospital for the first time may wish to be fully involved in their care (Sousa et al 2013).

One of the 'eight dimensions of humanisation' that highlight the importance of being aware of every family's background and individual circumstances is 'uniqueness' (Hemingway et al 2012). This dimension encourages nurses to take into consideration a person's family, home situation and background, and thereby avoid viewing them in isolation from their life context (Hemingway et al 2012).

Limitations Many of the studies included in the authors' literature review used interviews and/or questionnaires to collect data. Although these are valuable tools, enabling the researcher to obtain direct responses about the participants' perceptions and beliefs (Harris and Brown 2010), they may not provide an accurate picture of what happens in real life. If data was collected by observing participants in real-life situations, for example, within the hospital environment, a more realistic picture of whether and how negotiation occurs in practice would be obtained.

It is important for future research in this area to consider the effects of different reasons for hospital admission. Around half of the primary research studies included in this review did not specify the reasons for admission, so the results of the studies cannot be generalised to specific childhood conditions.

It is also important to bear in mind that the roles of parents as participants in the care of their children are constantly evolving, for example, due to the increasing importance of community care or day care for children with complex needs (Harrison 2010). Furthermore, the diverse backgrounds and specific circumstances of individual families inevitably affect the parents' desired level of participation in care, and thus their needs on negotiation.

\section{Conclusion}

The delivery of children's nursing can be improved by making student and registered nurses aware of the importance of role clarification and negotiation. Nurses can then provide optimal quality care for hospitalised children and their parents or carers. For example, implementation of a checklist for nurses to complete with the parent/s at the time of admission would help the nurse to clarify the nursing and parental roles. 
Ideally, as it takes some time to acquire the skills necessary for negotiating, pre-registration nursing programmes would include this particular skill set within curricular content (Smith 2009). Perhaps one way to achieve this would be through giving preregistration nursing students feedback from parents about their personal experiences. Repper and Breeze (2007) found that pre-registration nursing students who received service user feedback during their training demonstrated higher levels of empathetic understanding and communication skills in practice compared with students who did not receive such feedback as part of their training.

Raising nurses' awareness of the consequences of lack of negotiation with parents will make them better equipped to implement effective negotiation, and so to provide higher-quality care. Parents in turn will have greater confidence in their ability to care for their children alongside nurses, resulting in faster recovery and discharge.

Negotiation between nurse and parent can improve their working partnership and reduce the likelihood of conflict caused by poor communication. Nevertheless, there still seems to be a marked absence of negotiation in the practice environment. Although there has been a positive shift in attitude towards family-centred care, more attention needs to be paid to ensuring that nurses' expectations of parental roles within the hospital environment are free from erroneous assumptions. Finally, there is a need for nurses to adopt a more focused, individualised approach to working in partnership and negotiating effectively with parents of hospitalised children.

\section{Implications for practice}

Negotiation of the roles of nurse and parent leads to improved quality of care for the hospitalised child

Clarification of what nurses and parents consider to be their respective roles when caring for a hospitalised child is a prerequisite for negotiation

- The family's background, life experiences and specific circumstances have a major influence on the effectiveness of negotiation, so must always be taken into consideration

Poor communication and failure to provide information are barriers to negotiation of care roles

\section{Online archive}

For related information, visit our online archive and search using the keywords

\section{Conflict of interest}

None declared

\section{References}

Aein F et al (2009) Parental participation and mismanagement: a qualitative study of child care in Iran. Nursing and Health Sciences. 11, 3, 221-227.

Avis M, Reardon R (2008) Understanding the views of parents of children with special needs about the nursing care their child receives when in hospital: a qualitative study. Journal of Child Health Care. 12, 1, 7-17.

Casey A (1988) A partnership with child and family. Senior Nurse. 8, 4, 8-9.

Corlett J, Twycross A (2006) Negotiation of parental roles within family-centred care: a review of the research. Journal of Clinical Nursing. 15, 10, 1,308-1,316.

Coyne I (2008) Disruption of parent participation: nurses' strategies to manage parents on children's wards. Journal of Clinical Nursing. 17, 23, 3,150-3,158.

Coyne I (2015) Families and health-care professionals' perspectives and expectations of family-centred care: hidden expectations and unclear roles. Health Expectations. $18,5,796-808$

Coyne I, Cowley S (2007) Challenging the philosophy of partnership with parents: a grounded theory study. International Journal of Nursing Studies. 44, 6, 893-904.

Davies R (2010) Marking the 50th anniversary of the Platt Report: from exclusion to toleration and parental participation in the care of the hospitalized child. Journal of Child Health Care. 14, 1, 6-23.
Department of Health (2003) Getting the Right Start: National Service Framework for Children. Standard for Hospital Services. DH, London. Espezel H, Canam C (2003) Parent-nurse interactions: care of hospitalized children. Journal of Advanced Nursing. 44, 1, 34-41.

Fisher M, Broome M (2011) Parent-provide communication during hospitalization. Journal of Pediatric Nursing. 26, 1, 58-69.

Harris L, Brown G (2010) Mixing interview and questionnaire methods: practical problems in aligning data. Practical Assessment, Research and Evaluation. 15, 1, 1-19.

Harrison T (2010) Family-centered pediatric nursing care: state of the science. Journal of Pediatric Nursing. 25, 5, 335-343.

Hemingway A et al (2012) Humanising nursing care: a theoretical model. Nursing Times. $108,40,26-27$.

Hopia $\mathrm{H}$ et al (2005) Child in hospital: family experiences and expectations of how nurses can promote family health. Journal of Clinical Nursing. 14, 2, 212-222.

Hughes M (2007) Parents' and nurses' attitudes to family-centred care: an Irish perspective. Journal of Clinical Nursing. 16, 12, 2341-2348.

Hummelinck A, Pollock K (2006) Parents' information needs about the treatment of their chronically ill child: a qualitative study. Patient Education and Counseling. 62, 2, 228-234.

James S et al (2013) Nursing Care of Children: Principles and Practice. Fourth edition. Saunders Elsevier, St Louis MO.
Lam L et al (2006) Parents' experiences of participation in the care of hospitalised children: a qualitative study. International Journal of Nursing Studies. 43, 5, 535-545. Lee $\mathbf{P}$ (2007) What does partnership in care mean for children's nurses? Journal of Clinical Nursing. 16, 3, 518-526.

Ministry of Health (1959) The Welfare of Children in Hospital: Platt Report. Her Majesty's Stationery Office, London.

Moore J, Kordick M (2006) Sources of conflict between families and health care professionals Journal of Pediatric Oncology Nursing. $23,2,82-91$

Nethercott S (1993) A concept for all the family. Family centred care: a concept analysis. Professional Nurse. 8, 12, 794-797.

Nursing and Midwifery Council (2010) Standards for Competence for Registered Nurses. NMC, London.

O’Haire S, Blackford J (2005) Nurses' moral agency in negotiating parental participation in care. International Journal of Nursing Practice. 11, 6, 250-256.

Paliadelis P et al (2005) Implementing familycentred care: an exploration of the beliefs and practices of paediatric nurses. Australian Journal of Advanced Nursing. 23, 1, 31-36.

Reeves E et al (2006) Parents' experiences of negotiating care for their technologydependent child. Journal of Child Health Care 10, 3, 228-239
Reis M et al (2010) Developing nurse/parent relationships in the NICU through negotiated partnership. Journal of Obstetric, Gynecologic, and Neonatal Nursing. 39, 6, 675-683.

Repper J, Breeze J (2007) User and carer involvement in the training and education of health professionals: a review of the literature. International Journal of Nursing Studies. 44, 3, 511-519.

Roden J (2005) The involvement of parents and nurses in the care of acutely-ill children in a non-specialist paediatric setting. Journal of Child Health Care. 9, 3, 222-240.

Royal College of Nursing (2012) Core Competences for Nursing Children and Young People. RCN, London.

Smith L (2009) Negotiation of care. In Smith L Coleman V (Eds). Child and Family-Centred Healthcare: Concept, Theory and Practice. Second edition. Palgrave Macmillan, Basingstoke.

Sousa P et al (2013) Parental perspectives on negotiation of their child's care in hospital. Nursing Children and Young People. $25,2,24-28$

Ygge B (2007) Nurses' perceptions of parental involvement in hospital care. Paediatric Nursing. 19, 5, 38-40.

Young J et al (2006) Negotiation of care for a hospitalised child: nursing perspectives. Journal of Neonatal, Paediatric and Child Health Nursing. 9, 3, 7-14. 